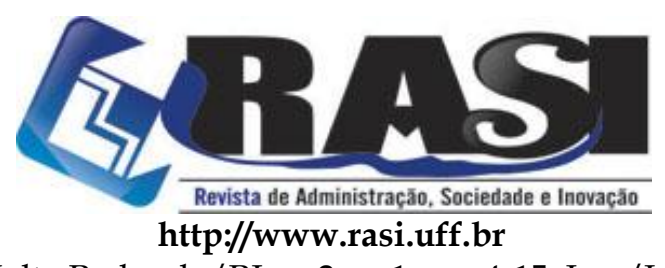

RASI, Volta Redonda/RJ, v. 2, n. 1, pp. 4-15, Jan./Jun. 2016

\title{
Análise do Uso de Instrumentos de Controladoria nos Empreendimentos Comerciais e Industriais, de São João Del-Rei - Minas Gerais
}

Eduardo Aguiar Silva, Fabrício Molica de Mendonça, Guilherme Vasconcelos e Gonçalves, Denise Carneiro dos Reis Bernardo

\section{RESUMO}

Este trabalho teve por objetivo analisar como os empreendimentos comerciais e industriais, fundados a partir de janeiro de 2010 vêm empregando instrumentos de controladoria no processo de tomada de decisão, desde a fase pré-operacional, de modo a verificar como tais instrumentos estão relacionados com o aumento das expectativas de vida e com a saúde financeira dessas empresas. Utilizou-se da pesquisa bibliográfica, documental e de campo. Os principais resultados dos trabalhos foram: a) a maioria das empresas na fase operacional não esteve preocupada com o uso de instrumentos de controladoria para o planejamento e controle de suas atividades; b) na fase operacional, há um maior uso de instrumentos ligados à função gerencial, que surgiu da necessidade de gerar informações para a tomada de decisões, no entanto, está limitado ao controle de estoques, de pagamentos e recebimento e de fluxo de caixa; c) há dificuldade em usar os instrumentos das demais funções - contábil, custos, tributária e proteção ao patrimônio - pela dificuldade em extrair as informações dos demonstrativos e dos documentos gerados pelos escritórios de contabilidade; d) as funções contábeis e tributárias têm sido desempenhadas pelos escritórios de contabilidade, com a finalidade apenas de cumprir as exigências da legislação. Conclui-se que, apesar de reconhecerem a importância da controladoria, suas ferramentas têm sido negligenciadas por empresários que, por falta de conhecimento, continuam tomando decisões com base em intuições. Estruturar um bom sistema de informação com base nas ferramentas da Controladoria é importante para garantir a sustentabilidade econômica e financeira desses empreendimentos ao longo do tempo.

PALAVRAS CHAVE: Controladoria, Empreendimentos, São João del-Rei.

\begin{abstract}
The main goal of this work was to analyze how commercial and industrial companies, which were founded after 2010, have been using controlling instruments in the decision-making process since preoperational phase, so that we could verify how these instruments are related with the increase in the life expectancy and the financial status of these companies. We performed a bibliographic, documentary and field research. The main results were: a) most companies in the pre-operational phase did not use controlling instruments for planning and activity control; b) in the operational phase, companies use more instruments related the managing function, since there was a need of generating information for decision-making actions, however, it is limited to stock, payment, receivement and cash flow control; c) it is difficult to use the instruments in the remaining functions - accounting, costs, tax and patrimony protection - since it is not straightforward to extract information about statemetns and documents generated by accounting offices; d) the accounting and tax functions have been performed by the accounting offices, with the only objective to obey legislation requirements. Then, we conclude that, although business owners acknowledge the importance of controlling functions, they have been neglecting the instrumentation available and keep making decision based on intuition. Organizing a good information system based on the controlling tools is important for ensure the economic and financial sustainability of long term companies.
\end{abstract}

KEYWORDS: Controlling, Entrepreneurship, São João del-Rei.

\section{Universidade
Federal
Fluminense}

R. Desembargador Ellis Hermydio Figueira, 783, Bloco A, sl. 218, Aterrado. 27213-415 - Volta Redonda, RJ - Brasil www.uff.br

Copyright (C) 2016 RASI. Todos os direitos, até mesmo de tradução, são reservados. É permitido citar parte de artigos sem autorização prévia, desde que seja identificada a fonte. 


\section{Análise do Uso de Instrumentos de Controladoria nos Empreendimentos Comerciais e Industriais, de São João Del-Rei - Minas Gerais}

\section{INTRODUÇÃO}

O Brasil é considerado um dos países que mais empreende no mundo, principalmente por meio de micro e pequenos negócios, que representam 99,5\% das empresas do país (SEBRAE, 2008).

No entanto, estudos realizados pelo SEBRAE (2008) revelam que 50\% dos empreendimentos abertos não atingem a maturidade, que é considerada um período superior a 42 meses. Uma explicação plausível se encontra no trabalho de GEM (2002) em relação ao tipo de empreendedorismo adotado no país. Segundo ele, em 2002, o Brasil possuía o posto de décimo sexto país do mundo em empreendedorismo por oportunidade e o primeiro em empreendedorismo por necessidade. Ressalta-se, que o empreendedorismo por oportunidade é aquele que está relacionado com a percepção de sucesso em um determinado segmento de mercado, já o empreendedorismo por necessidade relaciona-se uma alternativa de obtenção de renda.

De acordo com Antonik (2004), a sustentabilidade econômica e financeira é fundamental para o sucesso do empreendimento. Logo, necessita-se do uso dos instrumentos usados pela controladoria para auxílio na tomada de decisões, tais como: análise do fluxo de caixa; análise dos custos operacionais e financeiros; formação e análise de preços levando em consideração as taxas de juros e de inflação; análise dos indicadores econômico-financeiros e de orçamento.

Assim, cabe questionar até que ponto o uso de instrumentos da controladoria tem influenciado o tempo de vida dos empreendimentos comerciais e industriais com até cinco anos de atividade? Para responder tal questão é importante desenvolver estudos em regiões específicas, durante um período predeterminado, de modo que se tenha melhor controle das variáveis envolvidas. Por isso, limitou-se a desenvolver o trabalho junto aos empreendimentos comerciais e industriais da cidade de São João del-Rei, a partir do ano de 2010.

Assim, a hipótese básica que norteará este estudo é a de que os empreendimentos da cidade de São João del-Rei, criados a partir de 2010, que vem utilizando instrumentos de controladoria desde a idealização do negócio foram capazes de aumentar a expectativa de vida e chegar à fase de maturidade porque quanto mais estruturadas estiverem as informações, melhores serão as condições para a tomada de decisão, seja quanto ao preço dos produtos, quanto ao financiamento de novos investimentos, ou quanto a qualquer outra situação que envolva a tomada de decisão.

Para responder a essa questão, este trabalho teve por objetivo analisar como os empreendimentos comerciais e industriais, fundados a partir de janeiro de 2010 vêm empregando instrumentos de controladoria no processo de tomada de decisão, desde a fase pré-operacional, de modo a verificar como tais instrumentos estão relacionados com o aumento das expectativas de vida e com a saúde financeira dessas empresas.

A cidade de São João del-Rei foi escolhida em virtude do volume de microempresas comerciais e industriais, que desempenham papel de destaque na economia local, gerando emprego e renda para a população. Segundo o IBGE (2012), São João Del Rei possui 2906 empresas, que geram 21.701 empregos e 260.676 mil reais em salários e remunerações. 
Optou-se por restringir a pesquisa nas empresas criadas a partir de 2010 , de modo que pudesse reduzir o impacto da crise de 2008 na sobrevivência das empresas. Além disso, em virtude da dificuldade de acesso aos proprietários de empresas que fecharam suas portas durante esse período, o trabalho será desenvolvido apenas com as empresas que estão em funcionamento.

\section{REFERENCIAL TEÓRICO}

O termo empreendedorismo, debatido na literatura econômica, behaviorista e administrativa, está relacionado com a capacidade de criar riquezas (SMITH, 1776), desenvolver a economia (SAY, 1851) e inovar (SCHUMPETER, 1934). É definido como o processo de criar um negócio, até então, novo e desconhecido, assumindo todos os riscos e responsabilidades de lançar algo no mercado, seja um produto, serviço, comercio, empresa etc (SOUZA NETO, 2008, DOLABELA, 1999). O empreendedorismo identifica oportunidades e a transforma em algo rentável, que traga lucro, satisfação profissional e pessoal (MCCLELLAND, 1967) e, por isso, acaba contribuindo para o aumento da riqueza, gera emprego e renda, promove o crescimento econômico e melhora as condições de vida da população das cidades, regiões e países (BARON \& SHANE, 2008). Por isso, é considerado um motor de crescimento dentro do sistema capitalista (SCHUMPETER, 1934).

O Brasil apresenta uma taxa 15,4\% de empreendimentos em fase inicial, com até 42 meses de vida. Essa taxa é considerada alta quando comparada com os países emergentes - China (12,8\%), México (12,1\%), África do Sul (7,3\%) e Rússia (4,3\%) e mais alta, ainda, quando comparada às taxas de países desenvolvidos - Suíça $(5,9 \%)$, Alemanha (5,3\%), França (5,2\%), Itália (4,3\%) e Japão (4\%). Parte da explicação desse fenômeno do empreendedorismo no Brasil, de acordo com está relacionado com o sonho da população brasileira adulta em ter o seu próprio negócio (BOSMA, WENNEKERS e AMORÓS, 2012).

Segundo pesquisas desenvolvidas pelo SEBRAE (2008), metade dos empreendimentos abertos não atingem a maturidade, considerada superior a 42 meses de sobrevivência. O maior impacto acontece nos primeiros 12 meses, em que $27 \%$ das empresas fecham suas portas, seguidas por $11 \%$ de empresas que não chegam a alcançar 24 meses, $8 \%$ que não alcançam os 36 meses, $4 \%$ que não chegam aos 48 meses e $12 \%$ que não alcançam os 60 meses. No geral, é possível afirmar que, 62\% das empresas não conseguem concluir o quinto ano de atividade. Segundo SEBRAE-SP (2008), são abertas, em média, 133.581 e fechadas 87.663 empresas por ano, gerando perdas de 13,5 bilhões/ano em faturamento, 267 mil postos a menos de trabalho, portanto, a mortalidade de $66 \%$ das empresas abertas até o quinto ano de funcionamento e suas consequências apontam para limitações existentes nesse tipo de empreendedorismo praticado no país: o empreendedorismo por oportunidade e por necessidade.

O empreendedorismo por oportunidade surge da percepção de um empreendedor que lida com pesquisa e senso de análise de risco sobre um nicho de mercado ainda carente de produtos e serviços. Já o empreendedorismo por necessidade, a pessoa é muitas vezes motivada a empreender (investir ou participar de um projeto) como única alternativa para obtenção de renda e de sustento.

O empreendedorismo por necessidade é caracterizado pela falta de planejamento prévio adequado e gestão eficiente principalmente no que se refere ao plano financeiro, antes do início das atividades (GRECO, 2010), e a controladoria, relacionada ao 
acompanhamento e controle financeiro do negócio ao longo da vida da empresa (ANTONIK, 2004)

A controladoria pode ser entendida como um conjunto de princípios, métodos e procedimentos que ocupa da gestão econômica das empresas, com a finalidade de orientá-las para a eficácia (MOSIMANN E FISCH, 1999). Suas principais funções dentro da organização são: a) contábil relativa à contabilidade societária e financeira; b) Gerencial que compreende as atividades prover informações de natureza contábil, patrimonial, econômica, financeira e não-financeira voltadas para a tomadas de decisões gerenciais e estratégicas; c) Custos que compreende as atividades de registrar, mensurar, controlar, analisar e avaliar os custos da organização; d) Tributária relativa Contabilidade Tributária ou fiscal; e) Proteção e controle dos ativos que compreende as atividades referentes a prover proteção aos ativos além de controlá-los; f) Controle interno referentes ao estabelecimento e monitoramento do sistema de controles internos, destinado a proteger o patrimônio organizacional e salvaguardar os interesses da entidade; g) Controle de riscos que compreende as atividades de identificar, mensurar, analisar, avaliar, divulgar e controlar os diversos riscos envolvidos no negócio, bem como seus possíveis efeitos; h) Gestão da informação que compreende atividades relativas a conceber modelos de informações e gerenciar informações contábeis, patrimoniais, de custos, gerenciais e estratégicas (BORINELLI, 2006; MORANTE, 2008; KOLIVER, 2005). Tais funções são representadas por meio do Quadro 1.

\section{QUADRO 1: FUNÇÕES DA CONTROLADORIA NO AMBIENTE ORGANIZACIONAL}

\begin{tabular}{|l|l|}
\hline \multicolumn{1}{|c|}{ Funções } & \multicolumn{1}{c|}{ Atividades } \\
\hline Contábil & $\begin{array}{l}\text { Desenvolvimento da Contabilidade Societária (ou Financeira), dentre elas: gerenciar as } \\
\text { atividades de contabilidade, implementar e manter todos os registros contábeis } \\
\text { (processamento contábil) elaborar as demonstrações contábeis; }\end{array}$ \\
\hline Gerencial & $\begin{array}{l}\text { Coordenar, assessorar e consolidar os processos de elaboração dos planos empresariais, } \\
\text { orçamento e previsões; criar condições para a realização do controle, através do } \\
\text { acompanhamento dos planos e das decisões tomadas; auxiliar na definição de métodos e } \\
\text { processos para medição do desempenho das áreas organizacionais, assim como dos } \\
\text { gestores; auxiliar na definição e gestão de preços de transferência gerenciais; realizar } \\
\text { estudos sobre análise de viabilidade econômica de projetos de investimento; realizar } \\
\text { estudos especiais de natureza contábil-econômica; desenvolver condições para a } \\
\text { realização da gestão econômica e proceder à avaliação econômica. }\end{array}$ \\
\hline Custos & $\begin{array}{l}\text { As atividades de registrar, mensurar, controlar, analisar e avaliar os custos da } \\
\text { organização, incluindo análises gerenciais e estratégicas referentes à viabilidade de } \\
\text { lançamentos de produtos e serviços, resultados de produtos e serviços, de linhas de } \\
\text { negócios e de clientes. }\end{array}$ \\
\hline Tributária & $\begin{array}{l}\text { Atender às obrigações legais, fiscais e acessórias previstas em leis enormas tributárias, o } \\
\text { que significa registrar, apurar e controlar impostos, tributos contribuições, bem como } \\
\text { elaborar o Planejamento Tributário da organização. }\end{array}$ \\
\hline $\begin{array}{l}\text { Proteção e } \\
\text { controle de } \\
\text { ativos }\end{array}$ & $\begin{array}{l}\text { Prover proteção aos ativos, por meio da seleção, análise e contratação de opções de } \\
\text { seguros; registro de todos os bens da organização e avaliar o estágio de conservação. }\end{array}$ \\
\hline
\end{tabular}

Fonte: Borinelli (2006, p. 135-138). 


\section{METODOLOGIA}

\subsection{TIPO DE PESQUISA}

O método de abordagem utilizado foi o indutivo "em que [...] a generalização não deve ser buscada aprioristicamente, mas constatada a partir da observação de casos concretos suficientemente confirmados dessa realidade" (GIL, 2008 p.28). Para atender ao objetivo proposto, foi realizada uma pesquisa descritiva e explicativa, visando identificar os fatores de forma clara e em seguida verificar se estes determinam ou contribuem para a ocorrência dos fenômenos (GIL, 2008). Quanto aos procedimentos, foi realizada uma pesquisa empírica, com levantamento de dados primários, realizado por meio da pesquisa de campo. Neste caso, o levantamento de dados primários se justifica pelo conhecimento direto da realidade, pela economia e pela rapidez, além da quantificação dos dados (GIL, 2008).

Para atender ao objetivo proposto, foram usadas como técnicas a pesquisa bibliográfica, a pesquisa documental e a pesquisa de campo.

A pesquisa bibliográfica teve por finalidade compreender os fundamentos teóricos que envolvem os temas empreendedorismo e controladoria nas organizações. Em relação à controladoria, o parâmetro teórico foi embasado em suas funções: Contábil, GerencialEstratégica, Custos, Proteção e Controle dos Ativos, Controle Interno, Finanças e Gestão da Informação.

A pesquisa documental foi usada como base para o levantamento de informações em documentos elaborados pela Associação Comercial e Industrial da cidade de São João del-Rei, para obtenção de dados sobre o número de empresas que iniciaram e fecharam suas atividades a partir do ano de 2010 de modo a verificar o tempo médio de vida das empresas, o percentual de empresas que continuaram suas atividades.

A pesquisa de campo foi realizada por meio da aplicação de um questionário estruturado, contendo 196 questões objetivas. Aplicados, de forma individual, aos empresários das 72 empresas que aceitaram participar da pesquisa. Esse volume de entrevistados representou $74 \%$ do total das 97 empresas, participantes da Associação Comercial e Industrial de São João del-Rei, que permanecem no mercado a partir do ano de 2010.

A apresentação dos resultados foi feita por meio de tabelas, organizada por funções, contendo o percentual de respostas obtidas nas entrevistas. Por meio da interpretação dessas tabelas, foi possível verificar os instrumentos de controladoria usados pelos empresários; tanto na fase pré-operacional quanto na fase operacional (quadro 2) e, ainda, a forma como utilizam tais informações para a tomada de decisão.

\section{QUADRO 2: INSTRUMENTOS DE CONTROLADORIA}

\begin{tabular}{|c|c|c|}
\hline Funções & Instrumentos & Atividades \\
\hline Contábil & $\begin{array}{l}\text { - Softwares para a construção dos } \\
\text { demonstrativos contábeis } \\
\text { - Sistema de arquivamento dos } \\
\text { demonstrativos contábeis pela empresa } \\
\text { - Sistema de construção de demonstrativos } \\
\text { contábeis voltados para a tomada de } \\
\text { decisão, mesmo quando não exigidos } \\
\text { pela legislação; } \\
\text { - Balanço patrimonial para uso dos } \\
\text { gestores } \\
\text { - Demonstração de resultado mensal para } \\
\text { uso dos gestores }\end{array}$ & $\begin{array}{l}\text { Desenvolvimento da Contabilidade Societária } \\
\text { (ou Financeira), dentre elas: gerenciar as } \\
\text { atividades de contabilidade, implementar e } \\
\text { manter todos os registros contábeis } \\
\text { (processamento contábil) elaborar as } \\
\text { demonstrações contábeis; }\end{array}$ \\
\hline Gerencial & $\begin{array}{l}\text { - Planos empresariais } \\
\text { - Orçamento }\end{array}$ & $\begin{array}{l}\text { Coordenar, assessorar e consolidar os } \\
\text { processos de elaboração dos planos }\end{array}$ \\
\hline
\end{tabular}




\begin{tabular}{|c|c|c|}
\hline & $\begin{array}{l}\text { - Planilhas de controle de caixa, } \\
\text { - Planilha de controle de estoques } \\
\text { - Planilha de contas a receber e a pagar; } \\
\text { - Indicadores de desempenho das áreas da } \\
\text { organização } \\
\text { - Indicadores de desempenho dos gestores } \\
\text { - Indicadores de desempenho de resultados } \\
\text { - Estudo de análise de investimento } \\
\text { - Técnica de formação de preços } \\
\text { - Análise do Ponto de Equilíbrio }\end{array}$ & $\begin{array}{l}\text { empresariais, orçamento e previsões; criar } \\
\text { condições para a realização do controle, } \\
\text { através do acompanhamento dos planos e das } \\
\text { decisões tomadas; auxiliar na definição de } \\
\text { métodos e processos para medição do } \\
\text { desempenho das áreas organizacionais, } \\
\text { assim como dos gestores; auxiliar na } \\
\text { definição e gestão de preços de transferência } \\
\text { gerenciais; realizar estudos sobre análise de } \\
\text { viabilidade econômica de projetos de } \\
\text { investimento; realizar estudos especiais de } \\
\text { natureza contábil-econômica; desenvolver } \\
\text { condições para a realização da gestão } \\
\text { econômica e proceder à avaliação } \\
\text { econômica. }\end{array}$ \\
\hline Custos & $\begin{array}{l}\text { - Sistema de apuração de material direto } \\
\text { - Sistema de apuração de mão de obra } \\
\text { direta } \\
\text { - Sistema de levantamento de gastos } \\
\text { indiretos de fabricação } \\
\text { - Sistemas de custeio marginal variável ou } \\
\text { direto } \\
\text { - Sistema de custeio por absorção } \\
\text { - Indicadores de resultado de } \\
\text { produtos/serviços, } \\
\text { - Indicadores de linhas de negócios e de } \\
\text { cliente }\end{array}$ & $\begin{array}{l}\text { As atividades de registrar, mensurar, } \\
\text { controlar, analisar e avaliar os custos da } \\
\text { organização, incluindo análises gerenciais e } \\
\text { estratégicas referentes à viabilidade de } \\
\text { lançamentos de produtos e serviços, } \\
\text { resultados de produtos e serviços, de linhas } \\
\text { de negócios e de clientes. }\end{array}$ \\
\hline Tributária & $\begin{array}{l}\text { - Planilha de registro de tributos } \\
\text { - Arquivo de normas tributárias } \\
\text { envolvendo o setor ou ramo de atividade } \\
\text { - Planejamento tributário }\end{array}$ & $\begin{array}{l}\text { Atender às obrigações legais, fiscais e } \\
\text { acessórias previstas em leis e normas } \\
\text { tributárias, o que significa registrar, apurar e } \\
\text { controlar impostos, tributos contribuições, } \\
\text { bem como elaborar o Planejamento } \\
\text { Tributário da organização. }\end{array}$ \\
\hline $\begin{array}{l}\text { Proteção e } \\
\text { controle de } \\
\text { ativos }\end{array}$ & $\begin{array}{l}\text { - Seguros contratados } \\
\text { - Estudo de avaliação sobre contratação de } \\
\text { seguros } \\
\text { - Relação de todos os ativos existentes na } \\
\text { empresa } \\
\text { - Registro do estágio de conservação e } \\
\text { manutenção dos ativos }\end{array}$ & $\begin{array}{l}\text { Prover proteção aos ativos, por meio da } \\
\text { seleção, análise e contratação de opções de } \\
\text { seguros; registro de todos os bens da } \\
\text { organização e avaliar o estágio de } \\
\text { conservação. }\end{array}$ \\
\hline
\end{tabular}

Fonte: Adaptada pelos autores

\section{RESULTADOS E DISCUSSÕES}

\subsection{PERFIL DE EMPRESAS ASSOCIADAS A ACI A PARTIR DE 2010}

O estudo foi realizado com 72 empresas que fazem parte da Associação Comercial e Industrial de São João del-Rei (ACI-del-Rei), classificadas em açougues, padarias, bares e restaurantes, farmácias, indústrias e comércios em geral.

Quanto sua classificação contábil observa-se que $92 \%$ (89\% de micro e pequenas empresas e 2,8\% de Empresa de Pequeno Porte) estão enquadradas como $\mathrm{ME}^{1}$ ou $\mathrm{EPPs}^{2}$ no

\footnotetext{
${ }^{1}$ Considera-se Microempresa (ME) a pessoa jurídica que tenha auferido, no ano-calendário, receita bruta igual ou inferior a R\$360.000,00 (BRASIL, 2009)
} 
regime de tributação SIMPLES Nacional e 5,6\% estão enquadradas no Lucro Presumido e 2,8\% no lucro real.

Percebe-se que em $77,8 \%$ dessas micro e pequenas empresas, a gestão é realizada pelo proprietário e $22,2 \%$ a gestão é realizada por um gerente contratado. O número de gestores com curso superior é e $44 \%$ ( $36 \%$ completos e $8 \%$ incompletos), $28 \%$ possuem ensino médio completo, $22 \%$ possuem ensino fundamental completo e 5,6\% formação técnica em mecânica $(1,4 \%)$ e administração $(4,2 \%)$.

Classificando os gestores com curso superior, 23,6\% são formados em Administração, 4,2\% em Engenharia Mecânica, 2,8\% em Turismo, 1,4\% em Ciências Contábeis, 2,8\% em Informática e $1,4 \%$ em Direito.

Os motivos para a abertura do negócio foram diversos. 39\% declararam que o fator motivacional que fez com que abrissem o próprio negócio esteve relacionado a experiências técnicas em outros negócios de terceiros. $25 \%$ declararam que sempre tiveram vontade de ser dono do próprio negócio. $17 \%$ foram influenciados pela família. $11 \%$ buscaram tentar um negócio novo. $8 \%$ buscaram abrir um negócio dentro da área de formação.

\subsection{INSTRUMENTOS DE PLANEJAMENTO E CONTROLE USADOS PELAS EMPRESAS NAS FASES PRÉ OPERACIONAL E OPERACIONAL}

Para atender aos objetivos propostos neste trabalho, os instrumentos de controladoria foram classificados de acordo com suas funções: contábil, gerencial, custos, tributária e proteção e controle de ativos.

As tabelas apresentadas resumem o percentual de respostas dadas pelos entrevistados em relação aos instrumentos de controladoria usados por eles, dentro de cada função, na fase pré-operacional e na fase operacional.

\subsection{1 - Função contábil}

A função contábil é entendida como o centro da área de controladoria em virtude da contabilidade ser a responsável por recolher dados provenientes de todas as áreas da empresa, trata-los e armazená-los de acordo com princípios e normas legais e transformá-los em informações financeiras e econômicas capazes de oferecer aos gestores a base para a tomada de decisões.

Os resultados das entrevistas relacionados coma Função Contábil, apresentados na Tabela 1, revelam que apenas $22,2 \%$ dos entrevistados sabiam construir e fazer a leitura desses demonstrativos na fase pré-operacional e $25 \%$ sabem fazer tal construção e análise na fase operacional. Tais respostas vieram dos gestores que possuem formação em Administração (Superior e Técnico) e Ciências Contábeis. No entanto, tais profissionais afirmam que somente fazem a leitura desses demonstrativos, visto que, são elaborados por escritórios de contabilidade. Neste grupo também se encontram os que afirmam ter algum tipo de experiência com software da área de contabilidade, usados para a construção e análise de demonstrativos.

Os demais alegam que tais demonstrativos são elaborados pelos escritórios de contabilidade da cidade com a finalidade de atender a legislação fiscal e societária, porém, não conseguem ler as informações contidas neles. Como não entendem as informações transmitidas pelos demonstrativos contábeis, não conseguem extrair informações econômicas e financeiras voltadas para a tomada de decisão. O único item que conseguem entender é se a empresa deu lucro ou não. Mesmo assim, não conseguem entender porque o lucro nem sempre representa dinheiro em caixa ou no banco.

\footnotetext{
${ }^{2}$ Considera-se Empresa de Pequeno Porte (EPP) a pessoa jurídica que tenha auferido, no anocalendário, receita bruta igual ou inferior a $\mathrm{R} \$ 3.600 .000,00$ (BRASIL, 2009)
} 


\section{TABELA 1 - USO DE INSTRUMENTOS DA FUNÇÃO CONTÁBIL PELOS GESTORES NAS FASES PRÉ-OPERACIONAL E OPERACIONAL}

\begin{tabular}{|c|c|c|c|c|}
\hline & \multicolumn{2}{|c|}{ Fase Pré Operacional } & \multicolumn{2}{|c|}{ Fase Operacional } \\
\hline & Não & Sim & Não & Sim \\
\hline \multicolumn{5}{|l|}{ Função Contábil } \\
\hline Construção de Demonstrações Contábeis & $77,8 \%$ & $22,2 \%$ & $75 \%$ & $25 \%$ \\
\hline Leitura de Demonstrativos contábeis & $77,8 \%$ & $22,2 \%$ & $75 \%$ & $25 \%$ \\
\hline $\begin{array}{l}\text { Transformação de demonstrativos contábeis em } \\
\text { demonstrativos de tomada de decisão }\end{array}$ & $77,8 \%$ & $22,2 \%$ & $75 \%$ & $25 \%$ \\
\hline Experiência com uso de software contábil & $91,7 \%$ & $8,3 \%$ & $86,1 \%$ & $13,9 \%$ \\
\hline $\begin{array}{l}\text { Experiência com uso de software de transformação de dados } \\
\text { contábeis para dados de apoio gerencial }\end{array}$ & $86,1 \%$ & $13,9 \%$ & $86,1 \%$ & $13,9 \%$ \\
\hline
\end{tabular}

Fonte: Dados da pesquisa.

\subsection{2 - Função Gerencial}

Essa função da controladoria é a mais usada pelos gestores, apresentando maior percentual de representatividade nas respostas em relação ao seu uso, tanto na fase préoperacional quanto na fase operacional. Os instrumentos mais usados por eles são "Controle de Caixa", "Controle de estoques" e "Formação de Preço" (Tabela 2).

\section{TABELA 2 - USO DE INSTRUMENTOS DA FUNÇÃO GERENCIAL PELOS GESTORES NAS FASES PRÉ-OPERACIONA̧L E OPERACIONAL}

\begin{tabular}{|c|c|c|c|c|}
\hline & \multicolumn{2}{|c|}{ Fase Pré Operacional } & \multicolumn{2}{|c|}{ Fase Operacional } \\
\hline & Não & Sim & Não & Sim \\
\hline \multicolumn{5}{|l|}{ Função gerencial } \\
\hline Planilha de controle de caixa & $47,22 \%$ & $52,78 \%$ & $41,67 \%$ & $58,33 \%$ \\
\hline Planilha de levantamento de estoque & $52,78 \%$ & $47,22 \%$ & $44,44 \%$ & $55,56 \%$ \\
\hline Planilha de controle de contas a receber e a pagar & $44,44 \%$ & $55,56 \%$ & $44,44 \%$ & $55,56 \%$ \\
\hline Indicadores de desempenho de resultado & $63,89 \%$ & $36,11 \%$ & $27,78 \%$ & $72,22 \%$ \\
\hline Indicadores de análise do nível de liquidez & $75,00 \%$ & $25,00 \%$ & $16,67 \%$ & $83,33 \%$ \\
\hline Estudo de análise de investimentos & $72,22 \%$ & $27,78 \%$ & $75,00 \%$ & $25,00 \%$ \\
\hline Técnicas de formação de preço & $51,40 \%$ & $48,60 \%$ & $47,20 \%$ & $52,80 \%$ \\
\hline Levantamento e análise do ponto de equilíbrio & $75,00 \%$ & $25,00 \%$ & $75,00 \%$ & $25,00 \%$ \\
\hline Orçamento empresarial & $75,00 \%$ & $25,00 \%$ & $75,00 \%$ & $25,00 \%$ \\
\hline Plano de negócio & $75,00 \%$ & $25,00 \%$ & $0,00 \%$ & $0,00 \%$ \\
\hline
\end{tabular}

Fonte: Dados da pesquisa.

$\mathrm{Na}$ fase operacional, o aumento desses instrumentos surgiu naturalmente da própria necessidade de controle por parte do negócio, na visão dos gestores que passaram a adotá-los. No entanto, há ainda um percentual significativo de gestores que não usam tais instrumentos no controle diário e relatam que ficam perdidos em uma tomada de decisão. Acreditam que conseguem sobreviver no mercado por trabalharem com negócios rentáveis. Reconhecem que gostariam de entender melhor tais instrumentos para melhorar a gestão e afirma que estão dispostos a realizar treinamentos nessa área para melhorar a eficiência e a competitividade de suas empresas. 
Outros instrumentos dessa função que apresentaram crescimento significativo de uso foram os indicadores de resultado e de liquidez, mostrando a necessidade de controles constantes da liquidez e da rentabilidade da empresa, principalmente no que se refere a gestão do capital de giro. Para tais gestores, a própria necessidade de buscar recursos de curto e de longo prazo em bancos já desperta o interesse pelo controle desses indicadores.

Os estudos de análise de investimento e a elaboração e controle do plano de negócio reduziram significativamente. A explicação dada por eles é que tais instrumentos são usados apenas na fase operacional e fazem parte de exigências dos bancos para empréstimos e financiamentos. Tais gestores não sentem necessidade de atualizar e usar tais instrumentos para auxiliá-los na tomada de decisões. $25 \%$ acreditam no potencial desses instrumentos, mas não conseguem desenvolve-los sozinhos e não possuem tempo para dedicar a eles.

\subsection{3 - Função Custos}

As ferramentas atreladas a função de custos foram desenvolvidas, no geral, para a indústria e foram adaptadas para o comércio e para a prestação de serviços, com a finalidade de melhorar o controle e contribuir para o desenvolvimento de relatórios capazes de auxiliar a tomada de decisões. No entanto, analisando a Tabela 3, percebe-se que menos da metade das empresas conhecem seus custos diretos e indiretos de produção, comercial ou de prestação de serviços.

\section{TABELA 3 - USO DE INSTRUMENTOS DA FUNÇÃO DE CUSTOS PELOS GESTORES NAS FASES PRÉ-OPERACIONAL E OPERACIONAL}

\begin{tabular}{|c|c|c|c|c|}
\hline & \multicolumn{2}{|c|}{ Fase Pré Operacional } & \multicolumn{2}{|c|}{ Fase Operacional } \\
\hline & Não & Sim & Não & Sim \\
\hline \multicolumn{5}{|l|}{ Função de custos } \\
\hline Planilha de apuração de material direto & $75,0 \%$ & $25,0 \%$ & $72,2 \%$ & $27,8 \%$ \\
\hline Planilha de apuração de mão de obra direta & $75,0 \%$ & $25,0 \%$ & $75,0 \%$ & $25,0 \%$ \\
\hline Planilha de apuração de gastos indiretos & $80,6 \%$ & $19,4 \%$ & $80,6 \%$ & $19,4 \%$ \\
\hline Planilha de apuração de despesas & $63,9 \%$ & $36,1 \%$ & $58,3 \%$ & $41,7 \%$ \\
\hline Sistema de custeio marginal & $83,3 \%$ & $16,7 \%$ & $83,3 \%$ & $16,7 \%$ \\
\hline Sistema de custeio por absorção & $88,9 \%$ & $11,1 \%$ & $88,9 \%$ & $11,1 \%$ \\
\hline Indicadores de resultados & $66,7 \%$ & $33,3 \%$ & $66,7 \%$ & $33,3 \%$ \\
\hline Indicadores de linha de negócios e clientes & $77,8 \%$ & $22,2 \%$ & $77,8 \%$ & $22,2 \%$ \\
\hline
\end{tabular}

Fonte: Dados da pesquisa.

As despesas têm sido mais trabalhadas pelo comércio, no entanto, essa representação ainda é menor que $50 \%$, visto que apenas $41,7 \%$ das empresas que realizam esse controle. Os gestores relataram que há falta de tempo e de preparo para se dedicarem a esse tipo de controle. Alegaram também que os sistemas de controle são caros e de difícil operacionalização.

Tratando-se do conhecimento sobre sistemas de custeio, percebe-se desconhecimento das empresas em relação a eles. Somente $16,7 \%$ e $11,1 \%$ se utilizam dos sistemas como forma de planejamento tanto na fase pré operacional como na fase operacional. O levantamento de custos é feito de forma bastante simplificada, usando algumas informações sobre salários e materiais para estimar custos e lucros. As informações sobre os lucros acabam sendo passadas pelos escritórios de contabilidade que acabam não representando a realidade dessas empresas, principalmente quando comparam com os valores que estão depositados nas contas ou no caixa da empresa. 


\subsection{4 - Função Tributária}

A função tributária na controladoria tem sido usada por um volume menor que $30 \%$ das empresas entrevistadas (Tabela 4). O grupo envolve as empresas optantes pelo lucro real, lucro presumido, EPP e algumas microempresas. As demais atribuem a responsabilidade e controlar tributos e arquivar normas tributárias aos escritórios de contabilidade, que são externos às empresas. Tais empresas reduzem o planejamento tributário às atividades de apurar impostos sobre notas e realizar o pagamento desses impostos.

Pelo que se pode perceber, é que os escritórios de contabilidade da cidade de São João del-Rei assumem esse papel de controle de tributos. No entanto, não se pode afirmar, pela pesquisa realizada, se esses escritórios exercem de fato a função tributária de forma eficiente eficaz.

\section{TABELA 4 - USO DE INSTRUMENTOS DA FUNÇÃO TRIBUTÁRIA PELOS GESTORES NAS FASES PRÉ-OPERACIONAL E OPERACIONAL}

\begin{tabular}{|l|l|l|l|l|}
\hline & Fase Pré Operacional & \multicolumn{2}{c|}{ Fase Operacional } \\
\hline & Não & Sim & Não & Sim \\
\hline Função de tributária & & & & \\
\hline Planilha de controle de tributos & $77,8 \%$ & $22,2 \%$ & $69,4 \%$ & $30,6 \%$ \\
\hline Planejamento tributário & $75,0 \%$ & $25,0 \%$ & $72,2 \%$ & $27,8 \%$ \\
\hline Sistema de arquivamento de normas tributárias do setor & $77,8 \%$ & $22,2 \%$ & $77,8 \%$ & $22,2 \%$ \\
\hline
\end{tabular}

Fonte: Dados da pesquisa.

\subsection{5 - Função Proteção e controle de ativos}

Conforme pode ser visto por meio da Tabela 5 , a função de proteção e controle de ativos é outro conjunto de ferramentas que poucas empresas possuem conhecimento, visto que, $16,7 \%$ avaliam e contratam seguros e $22,2 \%$ das empresas mantém inventário de todos os ativos durante a fase operacional.

Um ponto de destaque é que $27,8 \%$ dos entrevistados afirmaram que mantinham o inventário de todos os seus ativos na fase pré-operacional e que este percentual caiu para $22,2 \%$ na fase operacional. Segundo tais entrevistados, essa queda se deve ao fato de que, na fase operacional, para efeitos de obtenção de recursos financeiros, foram obrigados a manter esse tipo de inventário. Na fase operacional, ao longo dos anos, as constantes trocas de máquinas e equipamentos, aliada à falta de tempo dos gestores, fizeram com que não fosse possível a manutenção desse inventário.

\section{TABELA 5 - USO DE INSTRUMENTOS DA FUNÇÃO PROTEÇÃO E CONTROLE DE ATIVOS PELOS GESTORES NAS FASES PRÉ-OPERACIONẢL E OPERACIONAL}

\begin{tabular}{|l|c|c|c|c|}
\hline & Fase Pré Operacional & \multicolumn{2}{|c|}{ Fase Operacional } \\
\hline Função de proteção e controle de ativos & Não & Sim & Não & Sim \\
\hline Avaliação de contratação de seguros & & & & \\
\hline Inventário de todos os ativos da empresa & $83,3 \%$ & $16,7 \%$ & $83,3 \%$ & $16,7 \%$ \\
\hline Registro de estágio de conservação e manutenção de ativos & $72,2 \%$ & $27,8 \%$ & $77,8 \%$ & $22,2 \%$ \\
\hline
\end{tabular}

Fonte: Dados da pesquisa 


\section{CONSIDERAÇÕES FINAIS}

Este trabalho teve por objetivo analisar como os empreendimentos comerciais e industriais, fundados a partir de janeiro de 2010, na cidade de São João del-Rei, vieram empregando instrumentos de controladoria no processo de tomada de decisão, desde a fase préoperacional, de modo a verificar como tais instrumentos estão relacionados com o aumento das expectativas de vida e com a saúde financeira dessas empresas.

Para atender aos objetivos propostos foram utilizadas a pesquisa bibliográfica, a pesquisa documental e a pesquisa de campo, por meio da aplicação de um entrevista estruturada, aplicada a 72 empresários que representa $74 \%$ de empresas, pertencentes a Associação Comercial e Industrial de São João del-Rei, fundadas a partir de 2010.

$\mathrm{Na}$ fase pré-operacional o uso de instrumentos da controladoria, na sua maioria, esteve ligado ao conhecimento de uma minoria de empresários em relação à gestão; às exigências de fontes de recursos financeiros para elaboração de algum tipo de projeto de investimento ou plano de negócio. No entanto, a maioria resolveu entrar no negócio motivada pela necessidade em abrir uma empresa aproveitando algum conhecimento técnico aprendido ou motivados por familiares e amigos. Sem, contudo, estarem preparados na área de gestão.

$\mathrm{Na}$ fase operacional, os instrumentos de controladoria que apresentaram aumento de uso por parte dos empresários estiveram relacionados com a função gerencial, limitando aos instrumentos controle de estoques, fluxo de caixa, controle de contas a pagar e a receber. Os indicadores relacionados a resultado e liquidez apresentaram crescimento significativo, por estarem ligados diretamente ao trade off liquidez versus rentabilidade.

As funções contábil e tributária não apresentaram evolução significativa pelas empresas. $\mathrm{E}$, pelos relatos, tais funções estão sendo desempenhadas pelos escritórios de contabilidade. No entanto, não foi possível, por meio dessa pesquisa, mostrar se tais escritórios têm desempenhado com eficiência tais funções, merecendo novas investigações.

Em relação a função de custos, as empresas apresentaram dificuldades em fazer a gestão dessa função em virtude de falta de conhecimento técnico na área de custos, se limitando aos demonstrativos enviados pela contabilidade.

Conclui-se que, apesar de reconhecerem a importância da controladoria, suas ferramentas têm sido negligenciadas por empresários que, por falta de conhecimento, continuam tomando decisões com base em intuições. Estruturar um bom sistema de informação com base nas ferramentas da Controladoria é importante para garantir a sustentabilidade econômica e financeira desses empreendimentos ao longo do tempo..

\section{REFERÊNCIAS}

ANTONIK, Luis Roberto. A Administração Financeira das Pequenas e Médias Empresas. Revista FAE BUSINESS, n. 8, p. 35-38, maio. 2004.

BARON, Robert A.; SHANE, Scott Andrew. Entrepreneurship: A Process Perspective: A Process Perspective. Cengage Learning, 2007.

BEDÊ, M. A; ALTOÉ, L. B. M. et al. Coleção Estudos e Pesquisas: Taxa de Sobrevivência das Empresas no Brasil. Brasília: SEBRAE, 2011.

BORINELLI, Márcio Luiz. Estrutura conceitual básica de controladoria: sistematização à luz da teoria e da práxis. 2006. 341 f. Tese (Doutorado em Ciências Contábeis) - Curso de Pós-graduação em Ciências Contábeis, Faculdade de Economia, Administração e Contabilidade, Universidade de São Paulo, São Paulo, 2006.

BOSMA, Niels; WENNEKERS, Sander; AMORÓS, José Ernesto. Global Entrepreneurship Monitor, 2011 Extended Report: Entrepreneurs and Entrepreneurial Employees Across 
the Globe. London: Global Entrepreneurship Research Association (GERA), 2012.

BRASIL. Lei Complementar n. 123, de 14 de dez 2006. Institui o Estatuto Nacional da Microempresa e da Empresa de Pequeno Porte, altera dispositivos das Leis 8.212 e 8.213, ambas de 24 de julho de 1991, da Consolidação das Leis do Trabalho _ CLT, aprovada pelo Decreto-Lei ${ }^{\circ} 5.452$, de $1^{\circ}$ de maio de 1943, da Lei $n^{\circ} 10.189$, de 14 de fevereiro de 2001, da Lei Complementar $\mathrm{n}^{\circ}$ 63, de 11 de janeiro de 1990; e revogada as Leis $\mathrm{n}^{\circ}$ 9.317, de 5 de dezembro de 1996, e 19.841, de 5 de outubro de 1999. Diário Oficial da União 31 de jan. 2009.

DOLABELA, Fernando. Oficina do empreendedor: a metodologia de ensino que ajuda a transformar conhecimento em riqueza. São Paulo: Cultura, 1999.

GEM Global Entrepreneurship Monitor Empreendedorismo no Brasil (GEM 2002). Instituto Brasileiro da Qualidade e Produtividade no Paraná, Relatório Executivo, Curitiba 2002.

GIL, Antônio Carlos. Métodos e técnicas de pesquisa social. Edição: 6. São Paulo: Atlas,2008. GRECO, S. M. S. S. et al. Empreendedorismo no Brasil (GEM 2010). IBQP: Curitiba, 2010. Instituto Brasileiro de Geografia e Estatística - IBGE. Cadastro Central de Empresas 2010. Rio de Janeiro: IBGE, 2012.

KOLIVER, Olívio. A contabilidade e a controladoria: tema atual e de alta relevância para a profissão contábil. Porto Alegre: Conselho Regional de Contabilidade do Rio Grande do Sul, 2005.

MCCLELLAND, David C. Achieving society. Simon and Schuster, 1967.

MORANTE, Antônio Salvador; JORGE, Fauzi Timaco. Controladoria: análise financeira, planejamento e controle orçamentário. São Paulo: Atlas, 2008. 164 p.

MOSIMANN, Clara P; FISCH, Sílvio. Controladoria: seu papel na administração de empresas. 2. ed. São Paulo: Atlas, 1999

SAY, Jean Baptiste; BIDDLE, Clement Cornell. A treatise on political economy. J. Grigg, 1851.

SCHUMPETER, Joseph A. Capitalism, socialism and democracy. Routledge, 2013.

SCHUMPETER, Joseph Alois. The theory of economic development: An inquiry into profits, capital, credit, interest, and the business cycle. Transaction Publishers, 1934.

SEBRAE-Serviço de Apoio às Micro e Pequenas Empresas de São Paulo. 10 Anos de Monitoramento da Sobrevivência e Mortalidade de Empresas. São Paulo: SebraeSP, 2008.

SMITH, Adam. An inquiry into the nature and causes of the wealth of nations: In two volumes. Cadell, 1776.

SOUZA NETO, Bezamat, Contribuição e elementos para um metamodelo empreendedor brasileiro: o empreendedorismo de necessidade do "virador". São Paulo: Blucher, 2008. 